\title{
Effect of carbohydrate type and concentration on polyhydroxy alcohol and trehalose content of conidia of three entomopathogenic fungi
}

\author{
John E. Hallsworth† and Naresh Magan \\ Author for correspondence: John E. Hallsworth. Tel: +4431449 5111. Fax: +44314513009.
}

Biotechnology Centre, Cranfield University, Cranfield, Bedford MK43 OAL, UK
The entomopathogenic fungi Beauveria bassiana, Metarhizium anisopliae and Paecilomyces farinosus were cultured on solid agar media containing different carbohydrate components (glycerol, glucose, trehalose or starch) at concentrations of $\leqslant 142.7 \mathrm{~g}$ added carbon $\mathrm{I}^{-1}$ for $30 \mathrm{~d}$ at $25^{\circ} \mathrm{C}$. The water activity $\left(a_{w}\right)$ of the media ranged from 0.925 to 0.998 . Growth of $M$. anisopliae and $P$. farinosus was stimulated between 0.975 and $0.995 a_{w}$ on glucose media and that of $\boldsymbol{P}$. farinosus at $0.975 \mathrm{a}_{\mathrm{w}}$ on glycerol media. At $<0.970 \mathrm{a}_{\mathrm{w}}$ growth of each fungal species was significantly reduced $(P<0.05)$. Polyhydroxy alcohols (polyols) and trehalose were extracted from conidia produced on different media and quantified using HPLC. Total polyol content of conidia produced on glucose media varied between 5.2 and $52.2 \mathrm{mg} \mathrm{g}^{-1}$ for B. bassiana, 77.3 and $90.3 \mathrm{mg} \mathrm{g}^{-1}$ for $M$. anisopliae, and 26.7 and $76.1 \mathrm{mg} \mathrm{g}^{-1}$ for $P$. farinosus. The amounts of specific polyols in conidia varied significantly from media of different glucose concentrations. Mannitol was the predominant polyol in conidia of all three species, with conidia of $M$. anisopliae, for example, containing as much as 75.2 mg mannitol $\mathbf{~ g}^{-1}$ when cultured on glucose media. The amount of the lower molecular mass polyols glycerol and erythritol was greater in conidia produced on glucose media with $>50.0 \mathrm{~g}$ added carbon $\mathrm{I}^{-1}$ than that in conidia produced at lower glucose concentrations. Conidia contained between 10.8 and $20.8 \mathrm{mg}$ glycerol plus erythritol $\mathrm{g}^{-1}$ on glucose media with $142.7 \mathrm{~g}$ added carbon $\mathrm{I}^{-1}$, depending on species. Conversely, conidia of B. bassiana and $P$. farinosus contained maximum amounts of trehalose $\left(\leqslant 23.5 \mathrm{mg} \mathrm{g}^{-1}\right.$ ) when produced on glucose media with $<50.0 \mathrm{~g}$ added carbon $\mathrm{I}^{-1}$, and trehalose content was considerably less at higher glucose concentrations. There were accumulations of glycerol and erythritol in conidia of all three species when grown on glycerol media with $>25.0 \mathrm{~g}$ added carbon $\mathrm{I}^{-1}$; conidia of B. bassiana contained up to $154 \cdot 0 \mathrm{mg}$ glycerol plus erythritol $\mathrm{g}^{-1}$. When $B$. bassiana and $P$. farinosus were grown on trehalose media, conidia contained up to $222.1 \mathrm{mg}$ trehalose $\mathrm{g}^{-1}$. By contrast, conidia of $M$. anisopliae contained $<17.0 \mathrm{mg}$ trehalose $\mathrm{g}^{-1}$ under all conditions tested. The water availability of solutions of different polyols is discussed in relation to their potential to act in osmotic adjustment during germination. The ability to manipulate polyol and trehalose content of fungal propagules may be critical in enhancing the storage life and efficacy of biological control agents.

Keywords: entomopathogenic fungi, polyhydroxy alcohol, trehalose, conidia, water activity

\section{INTRODUCTION}

Fungal biological control agents can be ineffective if

† Present address: Department of Biological Sciences, Heriot-Watt University, Riccarton, Edinburgh EH14 4AS, UK.

Abbreviation : $a_{w}$, water activity. conidia are unable to germinate because water availability is suboptimal (Walstad et al., 1970; Ferron, 1977; Doberski, 1981 ; Gillespie \& Crawford, 1986; Hsiao et al., 1992) or if they have inadequate carbohydrate reserves (Lane et al., 1991a; Harman et al., 1991). One way to overcome these problems is to modify the carbohydrate 
content of the fungal inocula (Harman et al., 1991; Hallsworth \& Magan, 1994). Polyhydroxyl alcohols (polyols) and trehalose can be important for successful germination and survival of desiccation during storage of propagules (Al-Hamdani \& Cooke, 1987; Harman ei al., 1991; Gornova et al., 1992). Polyols are known to accumulate to high concentrations in fungi at low water availability, and so reduce intracellular water activity $\left(\mathrm{a}_{\mathrm{w}}\right)$, while at the same time preventing enzyme inhibition due to dehydration (Brown, 1978; Yancey et al., 1982; Carpenter \& Crowe, 1988a). The disaccharide trehalose can replace water in membranes at reduced $a_{w}$ (Crowe et al., 1984; Tsvetkov et al., 1989; Crowe \& Crowe, 1993) and is known to stabilize enzyme structure during desiccation (Carpenter \& Crowe, 1988a, b; Colaco et cil., 1992). Polyols and trehalose are compatible with fungal metabolism; high intracellular concentrations do not destabilize or inhibit enzymes, so they are referred to as compatible solutes (Brown, 1976; Jennings \& Burke, 1990; Rudolph et al., 1993).

Ballio et al. (1964) reported on the polyol content of conidia (of Penicillium chrysogenum) but they did not consider the effects of carbohydrate source or water availability. Hallsworth \& Magan (1994) detailed changes in polyol and trehalose content of aerial conidia of Beauveria bassiana, Metarhizium anisopliae and Paecilomyces farinosus. These conidia were obtained from cultures: grown on media modified with the ionic solute $\mathrm{KCl}$ to give a range of water availabilities. Two recent studies examined the effect of medium composition on carbohydrate storage in total biomass and blastospores of the entomopathogen B. bassiana when grown in liquid culture (Bidochka et al., 1990; Lane et al., 1991a). Although Bidochka et al. (1990) found that the content of specific polyols in mycelium was enhanced by carbohydrate supplementation of the medium, no recognition was given to the role of polyols in osmotic adjustment and as compatible solutes.

An excess of exogenously supplied carbohydrate during nitrogen-substrate limitation can result in increased carbohydrate storage. Pfyffer \& Rast (1980) showed that nitrogen-substrate limitation enhanced polyol content in mycelia (or vegetative cells) of seven non-entomopathogenic fungi. Bidochka et al. (1990) and Lane et al. (1991a) found increased carbohydrate content of mycelia and blastospores of the entomopathogen B. bassiana under similar conditions. However, propagules such as blastospores and submerged conidia are less able to survive storage and resist environmental stress than aerial conidia, so the latter are of higher potential value for agricultural use (Lane et al., 1991b; Hegedus et al., 1992).

When the carbohydrate content of a medium is increased there is a reduction in water availability. Previous studies of the effect of carbohydrate type or concentration on the physiology of biological control agents have neglected consideration of this effect (Bidochka et al., 1990; Dillon \& Charnley, 1990; Jackson \& Bothast, 1990). Conversely, when $\mathrm{a}_{\mathrm{w}}$ has been adjusted by varying carbohydrate concentration in media, the potential effects of excess carbohydrate (e.g. those due to nitrogen-substrate limitation) have been ignored when considering the accumulation of specific polyols (Gervais et al., 1988; Van Eck et al., 1993).

The objectives of this study were to determine the effects of changing the concentration of glycerol, glucose, trehalose or starch in solid media, and of the resultant changes in $\mathrm{a}_{\mathrm{w}}$, on growth and accumulation of polyols and trehalose in conidia of $B$. bassiana, $M$. anisopliae and $P$. farinosus.

\section{METHODS}

Organisms and media. Fungal isolates were obtained from Horticulture Research International, Wellesbourne, UK ( $B$. bassiana 206) and Rothamsted Experimental Station, Harpenden, UK ( $M$. anisopliae V90 and $P$. farinosus V51). Stock cultures were stored at $5^{\circ} \mathrm{C}$ and had been subcultured up to eight times on Sabouraud dextrose agar (SDA) (Oxoid) after passage through an insect. Experimental media, based on SDA, contained (per l): $15.0 \mathrm{~g}$ agar no. 2 (Oxoid), $10.0 \mathrm{~g}$ mycological peptone (Lab M), a carbohydrate component (see below) and $21.3 \mathrm{~g}$ MES (Sigma). The $\mathrm{pH}$ of media was adjusted by addition of $2.5 \mathrm{M} \mathrm{NaOH}$ to give a final value of $5 \cdot 8 \pm 0 \cdot 3$. Media were autoclaved for $15.0 \mathrm{~min}$ at $121^{\circ} \mathrm{C}$, poured into $9.0 \mathrm{~cm}$ Petri plates $(15.0 \mathrm{ml})$ and cooled to $25^{\circ} \mathrm{C}$. The surface $\mathrm{pH}$ of media was measured using a pH stick (Gallenkamp). Either glycerol (Merck), glucose (Sigma), trehalose (Sigma) or soluble starch (Merck) was incorporated in media to give a range of 2.7 to $142.7 \mathrm{~g}$ added carbon $1^{-1}$, resulting in a range of 0.925 to $0.999 \mathrm{a}_{\mathrm{w}}$ at $25^{\circ} \mathrm{C}$ (Table 1). The $a_{w}$ of each medium was measured immediately before inoculation using a Novasina Humidistat IC II as theoretical predictions of $\mathrm{a}_{w}$, such as those made by Ellis $e t$ al. (1991), do not account for water lost upon pouring and cooling of media.

Culture conditions, growth assessment and collection of conidia. Petri plates were inoculated with $2.0 \mathrm{~mm}$ diameter mycelial plugs taken from the margin of 2-week-old cultures grown on $\mathrm{SDA}$ at $25^{\circ} \mathrm{C}$, and plates of the same $\mathrm{a}_{w}$ were incubated in sealed polyethylene bags at $25^{\circ} \mathrm{C}$ without light. Colony diameter was measured at intervals of $3 \mathrm{~d}$ and radial

\section{Table 1. Water activity $\left(a_{w}\right)$ of media with different} carbohydrate components

Values were means of three replicate measurements and variation was within $\pm 0.001 \mathrm{a}_{\mathrm{w}}$ unit. NA, Not applicable.

\begin{tabular}{|rcccc|}
\hline \multirow{2}{*}{$\begin{array}{c}\text { Added } \\
\text { carbon } \\
\text { (g 1 }^{-1} \text { ) }\end{array}$} & \multicolumn{5}{|c|}{ Water activity } \\
\cline { 3 - 5 } & Glycerol & Glucose & Trehalose & Starch \\
\hline 2.67 & 0.994 & 0.998 & NA & NA \\
15.85 & 0.986 & 0.995 & 0.999 & 0.999 \\
31.70 & 0.975 & 0.988 & NA & NA \\
43.59 & NA & NA & 0.993 & 0.993 \\
55.48 & 0.957 & 0.973 & NA & NA \\
95.10 & 0.925 & 0.959 & 0.980 & 0.982 \\
142.66 & NA & 0.939 & 0.970 & 0.975 \\
\hline
\end{tabular}


growth $\left(\mathrm{mm} \mathrm{d}^{-1}\right)$ calculated from the linear portions of the curves plotted from these values. Radial growth rate of filamentous fungi on solid media has been shown to relate directly to dry weight production over a range of $a_{w}$ (Griffin, 1977; Inch \& Trinci, 1987). This method of growth assessment was preferred to dry weight determination because the latter does not account for the substantial quantities of stored carbohydrates that may have been present in some treatments during this study. The dry weight of such storage material does not represent structural growth.

After $30 \mathrm{~d}$ conidia were collected. This was carried out initially by two methods: wet- and dry-harvesting. Conidia were wetharvested by flooding cultures with $10.0 \mathrm{ml}$ AnalaR water (Merck) containing $1 \%(\mathrm{v} / \mathrm{v})$ Tween 80 (Merck), dislodged by agitation with a glass rod and filtered through glass wool (see later). Dry-harvesting was carried out by gently scraping conidia from the surface of colonies using a spatula to avoid any possible dissolution of carbohydrates from media in the AnalaR water. Upon removal from the Petri plate, these conidia were placed into AnalaR water containing $1 \%$ Tween 80 , filtered, centrifuged and rinsed as described below. Suspensions of conidia were filtered through glass wool into $30.0 \mathrm{ml}$ Universal bottles and centrifuged immediately for $12.0 \mathrm{~min}$ at 4000 r.p.m. in a MSE Cenataur 2 centrifuge fitted with a four-place swing-out rotor. The glass wool was rinsed with AnalaR water prior to filtration to remove any loose fragments. Conidia were then resuspended in AnalaR water, recentrifuged as above, frozen to $-80^{\circ} \mathrm{C}$ upon removal from the centrifuge and then lyophilized in an Edwards EF4 Modulyo freeze dryer (Edwards High Vacuum International). There were three replicates of each treatment.

Polyol and trehalose content of conidia from cultures grown on 95.1 or $142.7 \mathrm{~g}$ added carbon $\mathrm{l}^{-1}$ was determined and there was no significant difference $(P<0 \cdot 05)$ between that of wet- or dryharvested conidia. Collection of conidia was subsequently carried out by wet-harvesting.

Extraction and detection of polyols and trehalose. Dry conidia ( $5 \mathrm{mg}$ ) were put into $2.0 \mathrm{ml}$ microfuge tubes containing $1.0 \mathrm{ml}$ AnalaR water and sonicated for $120 \mathrm{~s}$ at an amplitude of $28.0 \mu \mathrm{m}$ using a Fisons Soniprep 150, fitted with a $3.5 \mathrm{~mm}$ diameter exponential probe. After immersion in a boiling water bath for $5.5 \mathrm{~min}$, extracts were passed through a $0.2 \mu \mathrm{m}$ filter (Anatop).

Polyols and trehalose are weakly acidic at $\mathrm{pH} 14$ and were separated by anion exchange using a Dionex series 4500 HPLC instrument fitted with a CarboPac PA1 $(4 \times 250 \cdot 0 \mathrm{~mm})$ column, a CarboPac PA1 guard column and a Dionex pulsed electrochemical detector. The mobile phase (flow rate $1.0 \mathrm{ml} \mathrm{min} \mathrm{m}^{-1}$ ) was prepared by degassing Anala R water with $\mathrm{He}$ for $25.0 \mathrm{~min}$ after which $\mathrm{NaOH}$ was added to give a $100 \mathrm{mM}$ solution (pH approx. 14). Contamination of the mobile phase with $\mathrm{Na}_{2} \mathrm{CO}_{3}$ would accelerate elution of polyols and trehalose from the column and reduce resolution. Therefore, since $\mathrm{NaOH}$ pellets have a surface layer of $\mathrm{Na}_{2} \mathrm{CO}_{3}, \mathrm{NaOH}$ was obtained as a preprepared $50 \%\left(\mathrm{w} / \mathrm{w}\right.$ ) solution (Merck). The $\mathrm{Na}_{2} \mathrm{CO}_{3}$ content of a $50 \% \mathrm{NaOH}$ solution precipitates, so a pipette was inserted into the centre of the solution to avoid contamination with any precipitate on the inner surface of the container and, as a further precaution, the final third of each bottle was discarded. A $700 \mathrm{mM} \mathrm{NaOH}$ solution was prepared in the same way and used to flush the column daily and the electrode surface was cleaned with a plastic eraser. Injection volume was $50 \cdot 0 \mu \mathrm{l}$; peak areas were determined with a Hewlett-Packard 3390A integrator, with attenuation set at 10 . Detector sensitivity was adjusted to allow for variations of polyol and trehalose concentration. The limits of detection were 1.6 and $4.2 \mu \mathrm{g} \mathrm{ml}^{-1}$ for polyols, and $2 \cdot 8$ and $5.9 \mu \mathrm{g} \mathrm{ml}^{-1}$ for trehalose.

Standard solutions of glycerol (Merck), erythritol, arabitol, mannitol and trehalose (Sigma) were prepared and diluted to give a range of concentrations so that each injection of conidial extract was preceded and succeeded by injections of standards that could be detected at the same sensitivity. The polyol and trehalose content of conidia were calculated using the mean values of peaks from traces of standards that came immediately before and after sample traces, and values were expressed as $\mathrm{mg}(\mathrm{g} \text { conidia })^{-1}$. Each analysis was carried out with three replicates per treatment.

\section{RESULTS}

\section{Growth rate on different media}

Radial growth rate of each species of entomopathogen varied with carbohydrate type and concentration (Fig. 1). At $<31.7 \mathrm{~g}$ added carbon $\mathrm{I}^{-1} \mathrm{~B}$. bassiana and $M$. anisopliae grew significantly more slowly on glycerol than on glucose, trehalose or starch media $(P<0 \cdot 05)$. Intermediate concentrations of glucose or trehalose resulted in a stimulation of growth of $M$. anisopliae and $P$. farinosus, and the same phenomenon was seen on glycerol with $P$. farinosus. As the glycerol or glucose content of media was increased to $>40.0 \mathrm{~g}$ added carbon $1^{-1}$, there was a decrease in growth rate of each species. The decrease in growth rate on glucose media was less than on glycerol media at equivalent carbon concentration or $a_{w}$. On trehalose and starch media, as carbon content was increased, the growth rate of each fungus was not greatly reduced at $>40 \cdot 0$ g added carbon $\mathrm{l}^{-1}$ as it was on glycerol and glucose media.

\section{Polyols and trehalose in conidia from glycerol media}

On glycerol media with $95.1 \mathrm{~g}$ added carbon $\mathrm{l}^{-1}$, insufficient conidia of $B$. bassiana and $M$. anisopliae were produced for polyol and trehalose determination. As glycerol concentration was increased there were accumulations of glycerol and erythritol in conidia of each species. These were greatest for $B$. bassiana, where conidia contained as much as $96.0 \mathrm{mg}$ erythritol g $\mathrm{g}^{-1}$ and a total of $154 \cdot 0 \mathrm{mg}$ glycerol plus erythritol $\mathrm{g}^{-1}$ (Fig. 2). There were only trace amounts of polyols and trehalose in conidia obtained from cultures grown at $2.7 \mathrm{~g}$ added carbon $\mathrm{l}^{-1}$, except for those of $M$. anisopliae, which contained $115.0 \mathrm{mg}$ mannitol $\mathrm{g}^{-1}$. The decrease in the mannitol content in conidia of $M$. anisopliae from cultures grown at higher carbon concentrations was approximately equal in value to the combined increase in glycerol and erythritol in these conidia.

\section{Polyols and trehalose in conidia from glucose media}

Conidia of $B$. bassiana contained only trace amounts of polyols on media with $2 \cdot 7 \mathrm{~g}$ added carbon $\mathrm{l}^{-1}$ (Fig. 3). As glucose concentration was increased to $>50.0 \mathrm{~g} \mathrm{l}^{-1}$, the 


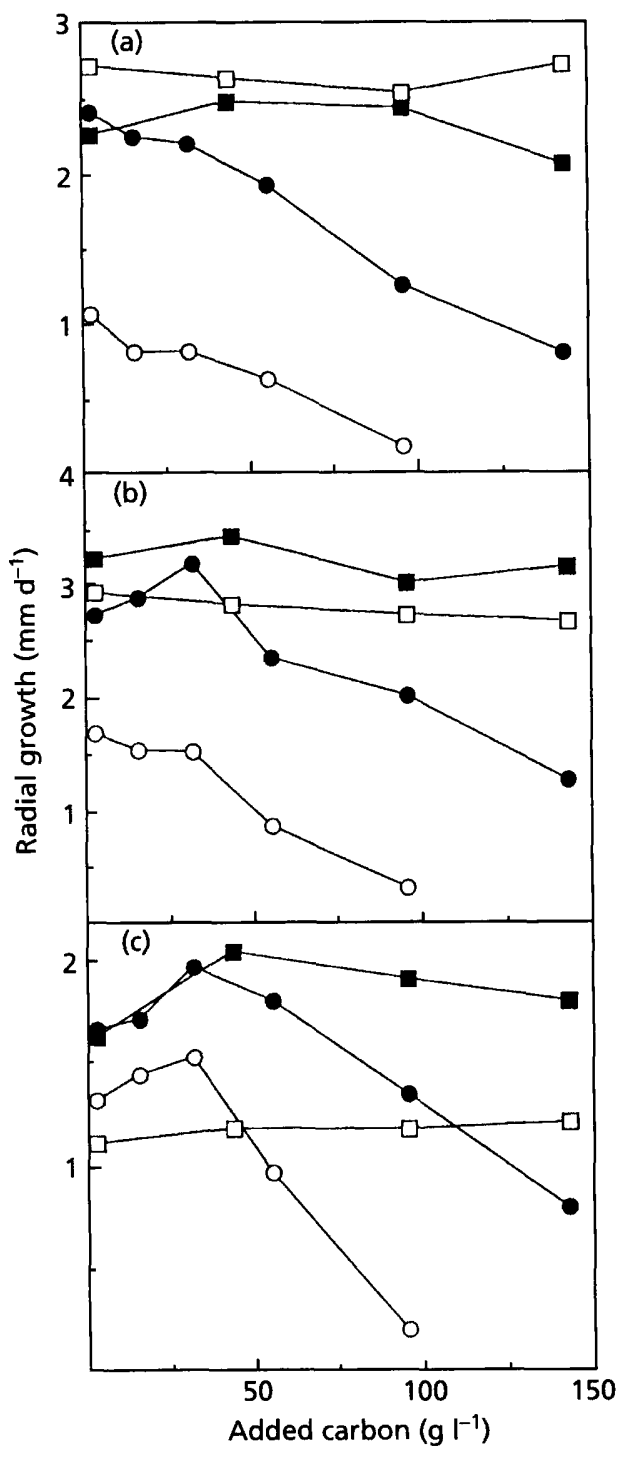

Fig. 1. Radial growth rates of (a) B. bassiana, (b) $M$. anisopliae and (c) $P$. farinosus grown on buffered SDA with a modified carbohydrate component at $25^{\circ} \mathrm{C}$. $\mathrm{O}$, Glycerol; $\boldsymbol{O}$, glucose; $\boldsymbol{\omega}$, trehalose; $\square$, starch. Results are means of three replicates; the least significant differences $(P<0.05)$ of growth rates on glycerol, glucose, trehalose and starch media were: (a) 0.13 , $0.19,0.18$ and $0.11 ;$ (b) $0.45,0.17,0.22$ and 0.14 ; and (c) 0.18 , $0.22,0.35$ and 0.23 , respectively.

mannitol content of conidia of all three fungi decreased from between 42.0 and $75.2 \mathrm{mg} \mathrm{g}^{-1}$ to between 22.0 and $37 \cdot 2 \mathrm{mg} \mathrm{g}^{-1}$, depending on species, and this decrease was accompanied by increases in erythritol and/or arabitol of approximately equal value. At low carbon concentrations, conidia of $B$. bassiana and $P$. farinosus contained as much as $23.5 \mathrm{mg}$ trehalose $\mathrm{g}^{-1}$.

\section{Polyols and trehalose in conidia from trehalose media}

As the trehalose content of media was increased, the erythritol or arabitol content of conidia increased in each

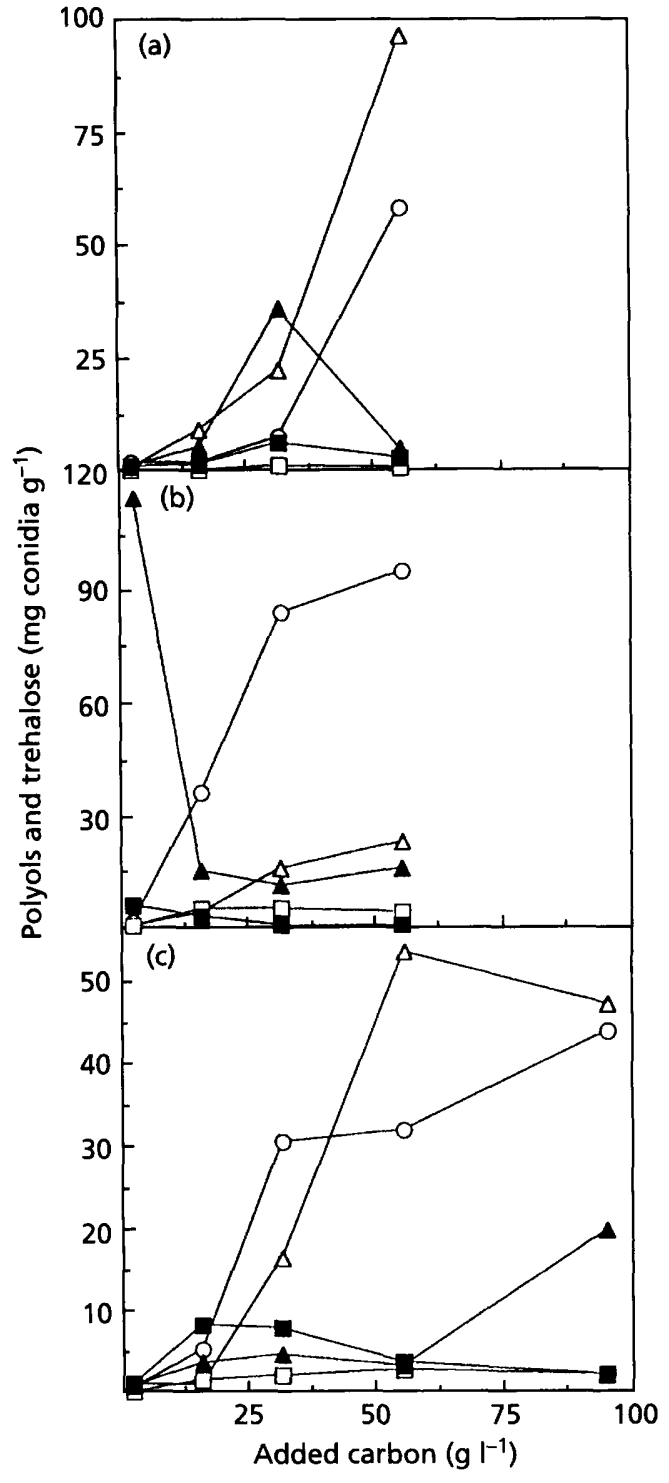

Fig. 2. Polyols and trehalose extracted from conidia of (a) $B$. bassiana, (b) $M$. anisopliae and (c) $P$. farinosus grown on buffered media with a variable glycerol content, after $30 \mathrm{~d}$ at $25^{\circ} \mathrm{C}$. O. Glycerol; $\triangle$, erythritol; $\square$, arabitol; $\boldsymbol{\Delta}$, mannitol; $\boldsymbol{\square}$, trehalose. Results are means of three replicates; the least significant differences $(P<0.05)$ for glycerol, erythritol, arabitol, mannitol and trehalose were: (a) 6.53, 9.67, 0.74, 5.64 and 2.02; (b) 10.73, 5.16, 2.07, 9.66 and 1.96; and (c) 7.59, 9.29, $1 \cdot 45,3 \cdot 70$ and $2 \cdot 17$, respectively.

species. Conidia of $M$. anisopliae contained $67.4 \mathrm{mg}$ arabitol $\mathrm{g}^{-1}$ at $142 \cdot 7 \mathrm{~g}$ added carbon $1^{-1}$ (Fig. 4). In $M$. anisopliae, the mannitol content of conidia decreased as arabitol content increased. Conidia of $B$. bassiana and $P$. farinosus contained significantly increased amounts of trehalose on media with $\geqslant 95.1 \mathrm{~g}$ added carbon $1^{-1}$ when compared to those from other media: 161.7 to $222 \cdot 1 \mathrm{mg} \mathrm{g}^{-1}$, respectively.

\section{Polyols and trehalose in conidia from starch media}

Mannitol was the predominant polyol in conidia of each 


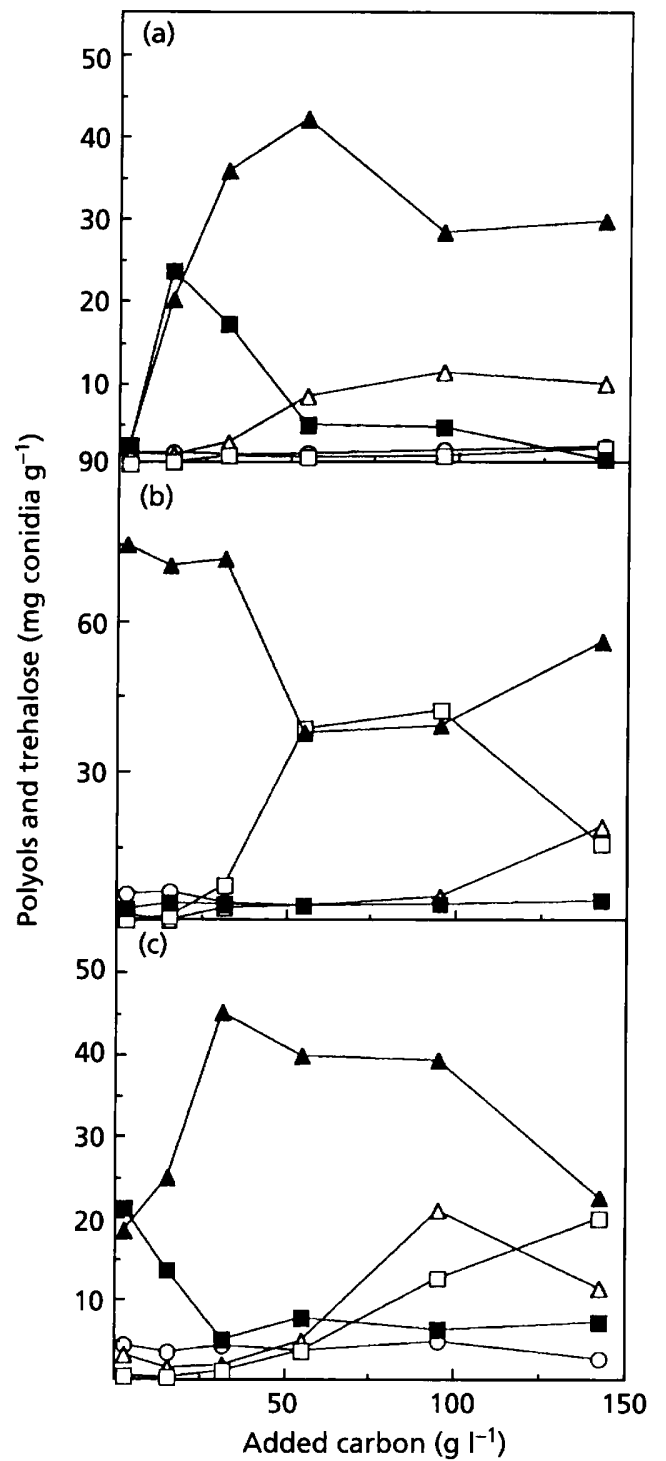

Fig. 3. Polyols and trehalose extracted from conidia of (a) $B$. bassiana, (b) $M$. anisopliae and (c) $P$. farinosus grown on buffered media with a variable glucose content, after $30 \mathrm{~d}$ at $25^{\circ} \mathrm{C}$. O. Glycerol; $\triangle$, erythritol; $\square$, arabitol; $\Delta$, mannitol; $\boldsymbol{\square}$, trehalose. Results are means of three replicates; the least significant differences $(P<0.05)$ for glycerol, erythritol, arabitol, mannitol and trehalose were: (a) 1.78, 1.25, 0.73, 4.33 and 2.78 ; (b) $1.54,3.45,2.84,6.71$ and 1.32 ; and (c) 1.69, 4.69, $1 \cdot 88,5 \cdot 76$ and $4 \cdot 43$, respectively.

species on starch media (Fig. 5). Conidia of B. bassiana contained as much as $49.2 \mathrm{mg}$ trehalose $\mathrm{g}^{-1}$ at $15.9 \mathrm{~g}$, added carbon $1^{-1}$, but lesser amounts when cultures were grown at higher carbon concentrations. As trehalose content of $B$. bassiana conidia decreased at higher carbon concentrations, mannitol content increased by a similar quantity.

\section{DISCUSSION}

\section{Growth rate on different media}

Nutrient utilization during fungal growth is most efficient

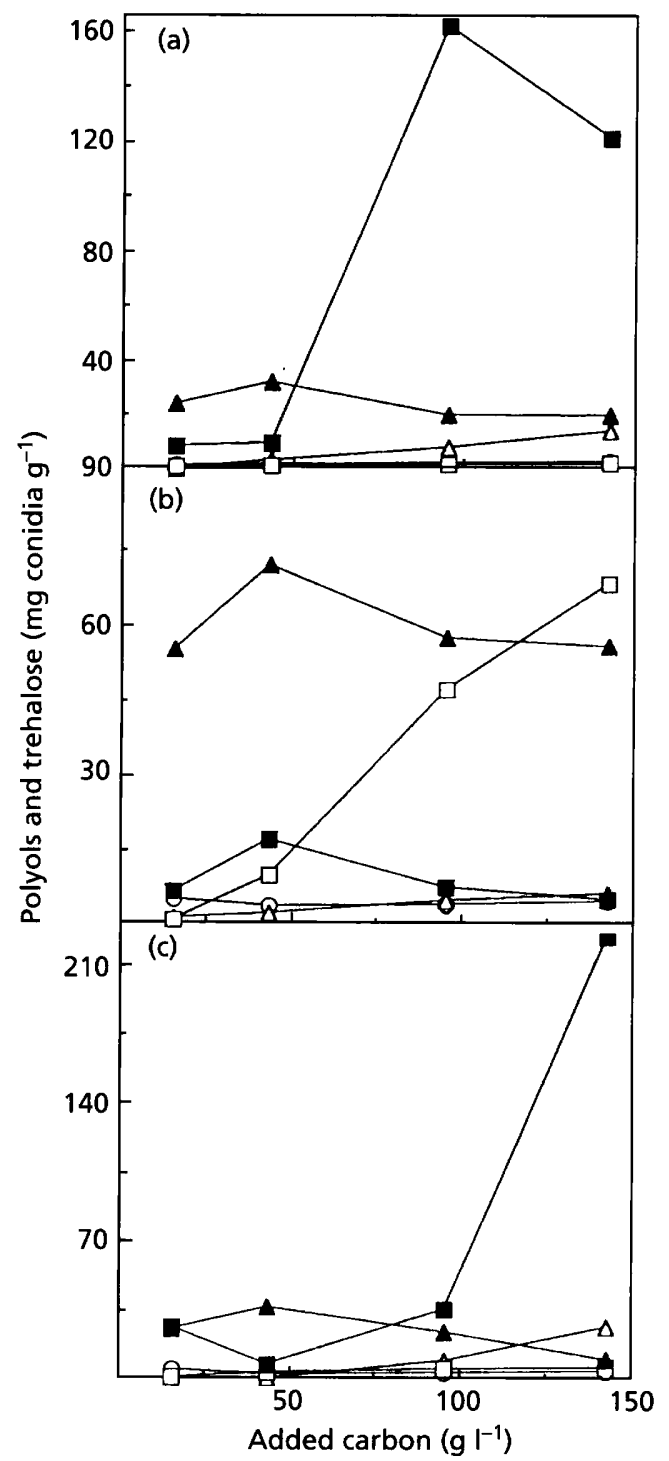

Fig. 4. Polyols and trehalose extracted from conidia of (a) $B$. bassiana, (b) $M$. anisopliae and (c) $P$. farinosus grown on buffered media with a variable trehalose content, after $30 \mathrm{~d}$ at $25^{\circ} \mathrm{C}$. O. Glycerol; $\triangle$, erythritol; $\square$, arabitol; $\boldsymbol{\Delta}$, mannitol; $\boldsymbol{\square}$, trehalose. Results are means of three replicates; the least significant differences $(P<0.05)$ for glycerol, erythritol, arabitol, mannitol and trehalose were: (a) 1.03, 2.11, 0.50, 5.90 and 11.65; (b) 3.00, 2.28, 5.22, 7.24 and 4.34; and (c) 1.53, 2.97, $1.63,5.87$ and $17 \cdot 36$, respectively.

when carbon and nitrogen are present in a ratio of about $8: 1$ (Roels, 1983). In this study, the total nitrogen content of all media was $1.3 \mathrm{~g} \mathrm{l}^{-1}$ and the carbon component from

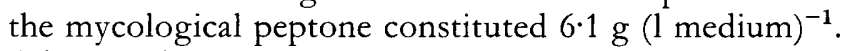
A balanced medium, therefore, would contain about $4.0 \mathrm{~g}$ added carbon $1^{-1}$, in the form of glycerol, glucose, trehalose or starch. In this study media containing $\geqslant 15.9 \mathrm{~g}$ added carbon $\mathrm{l}^{-1}$ contained an excess of carbon. As the added carbon content of trehalose and starch media was increased there was not a proportional increase in growth rate of the fungi, despite the high $\mathrm{a}_{\mathrm{w}}$ of all media $(\geqslant 0.970)$. This suggests that growth was nitrogensubstrate limited. 


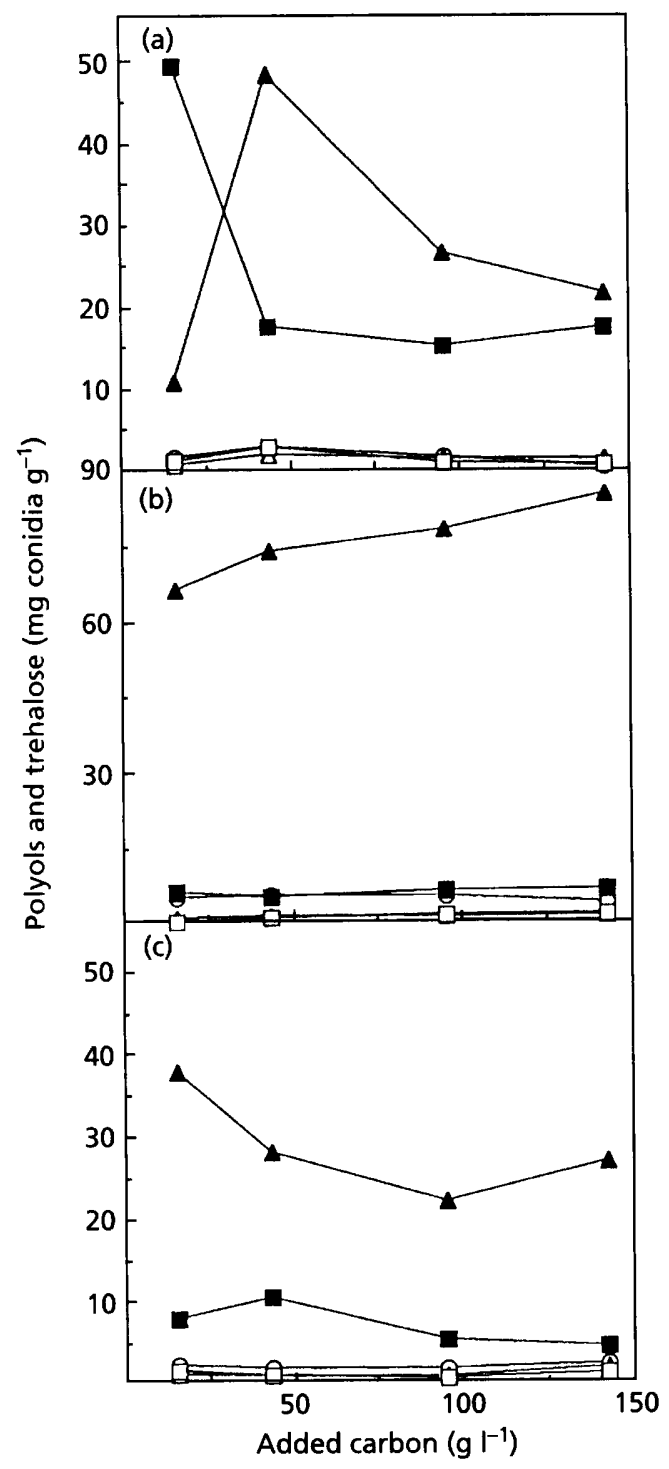

Fig. 5. Polyols and trehalose extracted from conidia of (a) $B$. bassiana, (b) $M$. anisopliae and (c) $P$. farinosus grown on buffered media with a variable starch content, after $30 \mathrm{~d}$ at $25^{\circ} \mathrm{C}$. 0 . Glycerol; $\triangle$, erythritol; $\square$, arabitol; $\mathbf{\Delta}$, mannitol; $\boldsymbol{\square}$, trehalose. Results are means of three replicates; the least significant differences $(P<0.05)$ for glycerol, erythritol, arabitol, mannitol and trehalose were: (a) $1.11,1.11,1.61,8.37$ and 5.76 ; (b) 2.74, 1.63, 1.41, 8.86 and 5.65; and (c) $3.13,1.72$, $2 \cdot 12,5 \cdot 43$ and $3 \cdot 92$, respectively.

Stimulation of growth of $P$. farinosus at intermediate $a_{w}$ values $(0.975-0.990)$ was similar to that reported on media modified with $\mathrm{KCl}$ (Hallsworth \& Magan, 1994), but not as marked. The stimulation of growth on media modified with $\mathrm{KCl}$ was seen in each fungal species and may have been due to a slight salt requirement (Larsen, 1986). Growth of B. bassiana, $M$. anisopliae and $P$. farinosus decreased progressively as the water availability was reduced to $<0.970 \mathrm{a}_{\mathrm{w}}$ as reported by Gillespie \& Crawford (1986) and Hallsworth \& Magan (1994). The reduction in growth rate per 0.010 reduction of $a_{w}$ was greater on glucose or $\mathrm{KCl}$ than on glycerol media for each species; this was most apparent in B. bassiana, where growth was reduced by $0.32 \mathrm{~mm} \mathrm{~d}^{-1}$ on glucose media, $0.25 \mathrm{~mm} \mathrm{~d}^{-1}$ on $\mathrm{KCl}$ media (Hallsworth \& Magan, 1994) but only $0.13 \mathrm{~mm} \mathrm{~d}^{-1}$ on glycerol media.

The relatively high growth rates at reduced $a_{w}$ on glycerol media may have been due to the intracellular accumulation of glycerol taken up from the medium which can act intracellularly in osmotic adjustment and as a compatible solute. Glycerol has frequently been used to reduce the water availability of media (Pitt \& Hocking, 1977; Hocking \& Pitt, 1979; Gillespie \& Crawford, 1986; Gervais et al., 1988; Mutasa et al., 1990). In these reports, the effects of reduced $a_{w}$ have been considered without recognition that fungi can utilize exogenously-supplied glycerol which may accumulate intracellularly and act as a compatible solute, thus mitigating the effects of reduced water availability.

\section{Polyols and trehalose in conidia from different media}

This study shows that the carbohydrate component and water status of the substrate significantly affect the quantities of specific polyols and trehalose in conidia of entomopathogens. Conditions under which conidia contained higher amounts of these compatible solutes were often not those under which optimal growth occurred; Bidochka et al. (1990) also made this observation in mycelia of liquid cultures of $B$. bassiana. HPLC was used to quantify polyols and trehalose in the present study and our previous study (Hallsworth \& Magan, 1994). By using this method it is possible to detect polyols and trehalose simultaneously. Furthermore, HPLC analysis avoids the derivatization of polyols that is necessary for GC detection.

In general, the greatest accumulation of polyols and trehalose in conidia occurred in the presence of excess carbon. Intracellular accumulation of carbohydrate reserves in nitrogen-substrate-limited liquid cultures of entomopathogens has been reported by Inch et al. (1986), Bidochka et al. (1990) and Lane et al. (1991a). In this study, the maximum content of polyols in conidia was 158.9 , 138.0 and $112.4 \mathrm{mg} \mathrm{g}^{-1}$ for B. bassiana, M. anisopliae and $P$. farinosus, respectively. By contrast, conidia from cultures of these fungal species grown on media with modified water availability contained considerably smaller amounts of polyols (Hallsworth \& Magan, 1994). Conidia of $P$. chrysogenum were found to contain $81.0 \mathrm{mg}$ polyols $\mathrm{g}^{-1}$, but no attempt was made to increase the carbon concentration or reduce the water availability of the medium (Ballio et al., 1964). Al-Hamdani \& Cooke (1987) found that sclerotia (mycelial propagules) of the plant pathogen Sclerotinia sclerotiorum contained as much as $269.7 \mathrm{mg}$ polyols $\mathrm{g}^{-1}$ when grown on media modified with $\mathrm{NaCl}$. Bidochka et al. (1990) found that mycelia of the entomopathogen $B$. bassiana contained $\leqslant 43.2 \mathrm{mg}$ polyols $\mathrm{g}^{-1}$, but the water availability of the media was not determined. Comparisons between the polyol content of conidia and that of mycelia or sclerotia are, however, of limited value due to the fundamental difference in the nature of these structures. 
Glucose has commonly been used as a carbohydrate source to culture B. bassiana, $M$. anisopliae and $P$. farinosus (Smith \& Grula, 1981; Gillespie \& Crawford, 1986; Humphreys et al., 1989; Hywel-Jones \& Gillespie, 1990; Lane et al., 1991a; Hallsworth \& Magan, 1994). In this study, as glucose concentration was increased, trehalose content of conidia of $B$. bassiana and $P$. farinosus decreased, whereas erythritol content increased to between 10.9 and $20.5 \mathrm{mg} \mathrm{g}^{-1}$, depending on species. These trends were probably a response to a reduction of $a_{w}$ rather than an effect of increased carbohydrate availability as they were identical to those seen when media were modified with $\mathrm{KCl}$ to reduce $\mathrm{a}_{\mathrm{w}}$ (Hallsworth \& Magan, 1994). They were also reported in sclerotia from cultures of $\dot{S}$. sclerotiorum grown over a range of $\mathrm{a}_{\mathrm{w}}$ on solid media modified with $\mathrm{KCl}$ or $\mathrm{NaCl}$ (Al-Hamdani \& Cooke, 1987). By contrast, Harman et al. (1991) found that the trehalose content of conidia of Trichoderma harzianum increased as $a_{w}$ was reduced when the medium was modified with polyethylene glycol (PEG) 6000.

The polyol component of conidia of $M$. anisopliae was composed of progressively lower $M_{\mathrm{r}}$ compounds as $\mathrm{a}_{\mathrm{w}}$ was reduced on glucose media, (this study) with $\mathrm{KCl}$ (Hallsworth \& Magan, 1994) or with PEG 600 (J. E. Hallsworth, unpublished data). Accumulation of progressively lower $M_{\mathrm{r}}$ polyols in fungi grown over a range of decreasing $a_{w}$ has been found in mycelia of nonentomopathogenic fungi (Beever \& Laracy, 1986; Kelly \& Budd, 1991). Although accumulations of low $M_{\mathrm{r}}$ polyols have frequently been reported in xerophilic fungi at reduced $\mathrm{a}_{\mathrm{w}}$ (Adler et al., 1982; Luard, 1982; Gadd et al., 1984; Hocking \& Norton, 1983; Hocking, 1986), water relations of such extremophiles do not typify the situation in other fungi. Protein structure in halophiles is, for example, different from that of non-halophilic organisms such as the entomopathogens in the present study (Yancey et al., 1982; Kushner, 1986). Adler et al. (1982) suggested that intracellular glycerol content of fungal cells may increase during salt stress whereas sugar-rich media may promote the accumulation of higher $M_{\mathrm{r}}$ polyols such as arabitol. This idea is not supported by the results of the present study or one in which the response to different media of the same $a_{w}$ were compared (Hallsworth \& Magan, 1994).

Van Lck et al. (1993) gave recognition to the ability of the lower $M_{\mathrm{r}}$ polyol glycerol to increase intracellular viscosity more effectively than higher $M_{\mathrm{r}}$ polyols, thereby acting as a more compatible solute (Chirife et al., 1984). Kelly \& Budd (1991) suggested that accumulations of lower $M_{\mathrm{r}}$ polyols may serve to economize on the carbon source for grow th and pointed out that shorter chain-length polyols have been shown to be more compatible (Brown, 1978). None of these studies, however, differentiated between the relative ability of different polyols to depress intracellular $\mathrm{a}_{\mathrm{w}}$ and this difference may, in part, account for the accumulation of lower $M_{\mathrm{r}}$ polyols in mycelia or propagules of cultures grown at reduced $a_{w}$.

Unsaturated solutions containing an equal amount of mannitol, arabitol, erythritol, and glycerol (in $\mathrm{g}^{-\mathbf{1}}$ ) have different $a_{w}$, and these polyols differ greatly in solubility, so their potential to depress intracellular $a_{w}$ varies. Mannitol is the least soluble, with a saturated solution having an $\mathrm{a}_{\mathrm{w}}$ of 0.978 at $25^{\circ} \mathrm{C}$ (Chirife et al., 1984). In conidia obtained from cultures grown on media at $<0.978 \mathrm{a}_{\mathrm{w}}$, mannitol would not enable depression of intracellular $a_{w}$ sufficiently to allow mycelial growth or germ tube elongation. Mannitol is, however, known to act as a compatible solute (Brown, 1978; Jennings \& Burke, 1990).

Arabitol is freely soluble and a saturated solution has an $a_{w}$ of 0.819 (Chirife et al., 1984). At a given concentration a solution of glycerol or erythritol would have a lower $a_{w}$ than that of arabitol or mannitol. The solubility of erythritol is limited; a saturated solution has an $a_{w}$ of 0.914 (J. E. Hallsworth, unpublished). However, erythritol is sufficiently soluble to depress intracellular $a_{w}$ to less than $0 \cdot 950$, a value below which conidia of $B$. bassiana, $M$. anisopliae and $P$. farinosus cannot normally germinate (Gillespie \& Crawford, 1986). Glycerol is miscible with water and, at a given concentration, a glycerol solution has a slightly lower $a_{w}$ than that of erythritol (J.E. Hallsworth, unpublished data). For this reason, in part, it seems likely that accumulations of lower $M_{\mathrm{r}}$ compounds such as erythritol and glycerol can confer greater osmotic tolerance than polyols such as mannitol.

It is noteworthy that the largest accumulations of low $M_{\mathrm{r}}$ polyols in this study were found in conidia obtained from glycerol media at growth-limiting $\mathrm{a}_{\mathrm{w}}$. Attempts to optimize growth of fungi in the agricultural production of inocula will not necessarily result in the production of good quality propagules, as low $M_{\mathrm{r}}$ polyols seem to accumulate in propagules obtained from growth-limited cultures grown at reduced $a_{w}$. Al-Hamdani \& Cooke (1987) compared germination of sclerotia obtained from such cultures grown on media of reduced $a_{w}$, with enhanced polyol content, with those from cultures grown at higher $a_{w}$. Sclerotia with enhanced polyol content germinated more vigorously than other sclerotia when tested on water agar, but germination was not assessed on media with reduced $a_{w}$.

Conidia from cultures grown on starch media $(\geqslant 0.970$ $a_{w}$ ) contained predominantly mannitol and very little erythritol and glycerol. This supports the idea that the accumulation of low $M_{\mathrm{r}}$ polyols in conidia obtained from cultures grown on glucose or trehalose media with $>50 \cdot 0 \mathrm{~g}$ added carbon $1^{-1}$ was a response to reduced $\mathrm{a}_{\mathrm{w}}$ and not a result of increased carbon concentration.

In his study, conidia obtained from cultures grown on trehalose media were found to contain up to $222 \cdot 1 \mathrm{mg}$ trehalose $\mathrm{g}^{-1}$, considerably more than those obtained from cultures grown on SDA modified with $\mathrm{KCl}$ (Hallsworth \& Magan, 1994). Trehalose is known to enhance desiccation tolerance. For example, conidia of $T$. harzianum and Aspergillus japonicus with an increased trehalose content retained viability during storage better 
than those containing less trehalose (Harman et al., 1991; Gornova et al., 1992). As conidia of B. bassiana and P. farinosus were found to accumulate trehalose significantly more than those of $M$. anisopliae, the potential to improve the storage life of agricultural inocula may vary between species. It is interesting to note that trehalose is the main carbohydrate in the insect haemolymph and so may be an important natural carbohydrate source (Mullins, 1985). Conidia produced on the insect cadaver may contain more trehalose than those produced either on glucose-based media such as SDA, or on starch-based substrates used in the production of agricultural inocula.

Conidia from all media were found to be viable and work is in progress to assess germination and virulence at low water availability. The ability to manipulate polyol and trehalose content of fungal propagules may be critical in the development of inocula of enhanced quality which have improved desiccation tolerance and storage life, and greater efficacy in the field.

\section{ACKNOWLEDGEMENTS}

Useful discussion was offered by R. E. Ashby, Professor D E. Brown, J. S. Talbot (Cranfield University) and Professor D. H. Jennings (University of Liverpool) and technical assistance given by A. Holden and V. Palmer. Fungal isolates were supplied by Dr T. M. Butt (Rothamsted Experimental Station) and Dr D. Chandler (Horticulture Research International). Financial support was received from Cranfield Biotechnology Ltd, a member of Enviromed plc.

\section{REFERENCES}

Adler, L., Pederson, A. \& Tunblad-Johansson, I. (1982). Polyol accumulation by two filamentous fungi grown at different concentrations of $\mathrm{NaCl}$. Pbysiol Plant 56, 139-142.

Al-Hamdani, A. M. \& Cooke, R. C. (1987). Effects of water potential on accumulation and exudation of carbohydrates and glycerol during sclerotium formation and myceliogenic germination in Sclerotinia sclerotiorum. Trans Br Mycol Soc 89, 51-60.

Ballio, A., Di Vittorio, v. \& Russi, S. (1964). The isolation of trehalose and polyols from the conidia of Penicillium chrysogenum Thom. Arch Biochem Biophys 107, 177-183.

Beever, R. E. \& Laracy, E. P. (1986). Osmotic adjustment in the filamentous fungus Aspergillus nidulans. J Bacteriol 168, 1358-1365.

Bidochka, M. J., Low, N. H. \& Khachatourians, G. G. (1990). Carbohydrate storage in the entomopathogenic fungus Beaweria bassiana. Appl Environ Microbiol 56, 3186-3190.

Brown, A. D. (1976). Microbial water stress. Bacterial Rev 40, 803-846.

Brown, A. D. (1978). Compatible solutes and extreme water stress in eukaryotic micro-organisms. Adv Microb Pbys 17, 181-242.

Carpenter, J. F. \& Crowe, J. H. (1988a). The mechanism of cryoprotection of proteins by solutes. Cryobiology 25, 244-255.

Carpenter, J. F. \& Crowe, J. H. (1988b). Modes of stabilization of : protein by organic solutes during desiccation. Cryobiology 25 $459-470$.
Chirife, J., Favetto, G. \& Fontan, F. (1984). Microbial growth at reduced water activities: some physiochemical properties of compatible solutes. J Appl Bacteriol 56, 259-268.

Colaco, C., Sen, S., Thangavelu, M., Pinder, S. \& Roser, B. (1992). Extraordinary stability of enzymes dried in trehalose: simplified molecular biology. Bio/Technology 10, 1007-1011.

Crowe, J. H. \& Crowe, L. M. (1993). Evidence for direct interaction between disaccharides and dry phospholipids. Cryobiology 30, 226-227.

Crowe, J. H., Crowe, L. M. \& Chapman, D. (1984). Preservation of membranes in anhydrobiotic organisms: the role of trehalose. Science 223, 701-703.

Dillon, R. J. \& Charnley, A. K. (1990). Initiation of germination in conidia of the entomopathogenic fungus, Metarbizium anisopliae. Mycol Res 94, 299-304.

Doberski, J. W. (1981). Comparative laboratory studies on three fungal pathogens of the elm bark beetle Scolytus scolytus: effect of temperature and humidity on infection of Beaweria bassiana, Metarbizium anisopliae and Paecilomyces farinosus. J Invertebr Pathol 37, 195-200.

Ellis, S. W., Grindle, M. \& Lewis, D. H. (1991). Effect of osmotic stress on yield and polyol content of dicarboximide-sensitive and -resistant strains of Neurospora crassa. Mycol Res 95, 457-464.

Ferron, P. (1977). Influence of relative humidity on the development of fungal infection caused by Beauveria bassiana (Fungi Imperfecti, Moniliales) in imagines of Acanthoscelides obtectus (Col. : Bruchidae). Entomophaga 22, 393--396.

Gadd, G. M., Chudek, J. A., Foster, R. \& Reed, R. H. (1984). The osmotic responses of Penicillium ochro-chloron: changes in internal solute levels in response to copper and salt stress. J Gen Microbiol 130, 1969-1975.

Gervais, P., Molin, P., Grajek, W. \& Bensoussan, M. (1988). Influence of the water activity of a solid substrate on the growth rate and sporogenesis of filamentous fungi. Biotechnol Bioeng 31, 457-463.

Gillespie, A. T. \& Crawford, E. (1986). Effect of water activity on conidial germination and mycelial growth of Beaweria bassiana, Metarbizium anisopliae, Paecilomyces spp. and Verticillium lecanii. In Fundamental and Applied Aspects of Invertebrate Pathology. Edited by R. A. Samson, J. M. Vlak \& D. Peters, p. 254. Wageningen: Society of Invertebrate Pathology.

Gornova, I. B., Feofilova, E. P., Tereshina, V. M., Golovina, E. A., Krotkova, N. B. \& Kholodova, V. P. (1992). Effect of carbohydrate content of Aspergillus japonicus spores on their survival in storage and subsequent germination. Mikrobiologiya 61, 549-554.

Griffin, D. M. (1977). Water potential and wood-decay fungi. Annu Rev Pbytopatbol 15, 319-329.

Hallsworth, J. E. \& Magan, N. (1994). Effects of $\mathrm{KCl}$ concentration on accumulation of acyclic sugar alcohols and trehalose in conidia of three entomopathogenic fungi. Lett Appl Microbiol 18, 8-11.

Harman, G. E., Jin, X., Stasz, T. E., Peruzzotti, G., Leopold, A. C. \& Taylor, A. G. (1991). Production of conidial biomass of Trichoderma barzianum for biological control. Biol Control 1, 23-28.

Hegedus, D. D., Bidochka, M. J., Miranpuri, G. S. \& Khachatourians, G. G. (1992). A comparison of the virulence, stability and cell-wall-surface characteristics of three spore types produced by the entomopathogenic fungus Beaweria bassiana. Appl Microbiol Biotechnol 36, 785-789. 
Hocking, A. D. (1986). Effects of water activity and culture age on the glycerol accumulation patterns of five fungi. J Gen Microbiol 132, 269-275.

Hocking, A. D. \& Norton, R. S. (1983). Natural-abundance ${ }^{13} \mathrm{C}$ nuclear magnetic resonance studies on the internal solutes of xerophilic fungi. J Gen Microbiol 129, 2915-2925.

Hocking, A. D. \& Pitt, J. I. (1979). Water relations of some Penicillium species at $25^{\circ} \mathrm{C}$. Trans Br Mycol Soc 73, 141-145.

Hsiao, W. F., Bidochka, M. J. \& Khachatourians, G. G. (1992). Effect of temperature and relative humidity on the virulence of the entomopathogenic fungus, Verticillium lecanii, toward the oat-bird aphid, Rhopalosiphum padi (Hom., Aphididae). J Appl Entomol 114, 484-490.

Humphreys, A. M., Matewele, P., Trinci, P. J. \& Gillespie, A. T. (1989). Effects of water activity on morphology, growth and blastospore production of Metarbizium anisopliae and Paecilomyces farinosus in batch and fed-batch culture. Mycol Res 92, 257-264.

Hywel-Jones, N. L. \& Gillespie, A. T. (1990). Effect of temperature on spore germination in Metarbizium anisopliae and Beauveria bassiana. Mycol Res 94, 389-392.

Inch, J. M. M. \& Trinci, A. P. J. (1987). Effects of water activity on growth and sporulation of Paecilomyces farinosus in liquid and solid media. J Gen Microbiol 133, 247-252.

Inch, J. M. M., Humphreys, A. M., Trinci, A. P. J. \& Gillespie, A. T. (1986). Growth and blastospore formation by Paecilomyces fumosorosetts, a pathogen of brown planthopper (Nilaprvata lugens). Trans Br Mrcol Soc 87, 215-222.

Jackson, M. A. \& Bothast, R. J. (1990). Carbon concentration and carbon-to-nitrogen ratio influence submerged culture conidiation by the potential bioherbicide Colletotrichum trucatum NRRL 13737. Appl Environ Microbiol 56, 3435-3438.

Jennings, D. H. \& Burke, R. M. (1990). Compatible solutes - the mycological dimension and their role as physiological buffering agents. New Pbytol 116, 277-283.

Kelly, D. J. A. \& Budd, K. (1991). Polyol metabolism and osmotic adjustment in the mycelial ascomycete Neocosmospora vasinfecta (E. F. Smith). Exp Mycol 15, 55-64.

Kushner, D. J. (1986). Molecular adaptation of enzymes, metabolic systems and transport systems in halophilic bacteria. FEMS Microbiol Rev 39, 121-127.

Lane, B. S., Trinci, A. P. J. \& Gillespie, A. T. (1991a). Endogenous reserves and survival of blastospores of Beauveria bassiana harvested from carbon- and nitrogen-limited batch cultures. Mycol Res 95, 821828 .

Lane, B. S., Trinci, A. P. J. \& Gillespie, A. T. (1991b). Influence of cultural conditions on the virulence of conidia and blastospores of
Beauveria bassiana to the green leafhopper Nephotettix virescens. Mycol Res 95, 829-833.

Larsen, H. (1986). Halophilic and halotolerant microorganisms an overview and historical perspective. FEMS Microbiol Rev 39, 3-7.

Luard, E. J. (1982). Accumulation of intracellular solutes by two filamentous fungi in response to growth at low steady state osmotic potential. J Gen Microbiol 128, 2563-2574.

Mullins, D. E. (1985). Chemistry and physiology of the haemolymph. In Comprehensive Insect Physiology, Biochemistry and Pbarmacology. Edited by G. A. Kerkut \& L. I. Gilbert, pp. 355-392. Oxford: Pergamon Press.

Mutasa, E. S., Magan, N. \& Seal, K. J. (1990). Effects of potassium sorbate and environmental factors on growth of tobacco spoilage fungi. Mycol Res 94, 971-978.

Pfyffer, G. E. \& Rast, D. M. (1980). The polyol pattern of some fungi not hitherto investigated for sugar alcohols. Exp Mycol 4, $160-170$.

Pitt, J. I. \& Hocking, A. D. (1977). Influence of solute and hydrogen ion concentration on the water relations of some xerophilic fungi. $J$ Gen Microbiol 101, 35-40.

Roels, J. A. (1983). Energetics and Kinetics in Biotecbnology. Amsterdam: Elsevier University Press.

Rudolph, A. S., Cliff, R. O. \& Spargo, B. J. (1993). The use of compatible solutes in the long-term preservation of lipid microstructures. Cryobiology 30, 236-237.

Smith, R. J. \& Grula, E. A. (1981). Nutritional requirements for conidial germination and hyphal growth of Beauveria bassiana. $J$ Invertebr Pathol 37, 222-230.

Tsvetkov, T. D., Tsomnev, L. I., Tsvetkova, N. M., Koynova, R. D. \& Tenchov, B. G. (1989). Effect of trehalose on the phase properties of hydrated and lyophilized dipalmitoylphosphatidylcholine multilayers. Mikrobiologiya 53, 155-159.

Van Eck, J. H., Prior, B. A. \& Brandt, E. V. (1993). The water relations of growth and polyhydroxy alcohol production by ascomycetous yeasts. J Gen Microbiol 139, 1047-1054.

Walstad, J. D., Anderson, R. F. \& Stambaugh, W. J. (1970). Effects of environmental conditions on two species of muscardine fungi (Beauveria bassiana and Metarbizium anisopliae). J Invertebr Pathol 16, 221-226.

Yancey, P. H., Clark, M. E., Hand, S. C., Bowlus, R. D. \& Somero, G. N. (1982). Living with water stress: evolution of osmolyte systems. Science 217, 1214-1222.

Received 1 February 1994; accepted 18 May 1994. 